\title{
BMJ Open Medication safety risks to be managed in national implementation of automatic substitution of biological medicines: a qualitative study
}

\author{
Hanna M Tolonen (D) , ${ }^{1,2}$ Marja SA Airaksinen, ${ }^{1}$ Päivi Ruokoniemi, ${ }^{3}$ \\ Katri Hämeen-Anttila, ${ }^{3}$ Kenneth M Shermock, ${ }^{4,5}$ Pekka Kurki ${ }^{6}$
}

To cite: Tolonen HM, Airaksinen MSA, Ruokoniemi P, et al. Medication safety risks to be managed in national implementation of automatic substitution of biological medicines: a qualitative study. BMJ Open 2019;9:e032892. doi:10.1136/ bmjopen-2019-032892

- Prepublication history and additional material for this paper are available online. To view these files, please visit the journal online (http://dx.doi. org/10.1136/bmjopen-2019032892).

Received 11 July 2019 Revised 06 September 2019 Accepted 24 September 2019

Check for updates

(C) Author(s) (or their employer(s)) 2019. Re-use permitted under CC BY-NC. No commercial re-use. See rights and permissions. Published by BMJ.

For numbered affiliations see end of article.

Correspondence to

Hanna M Tolonen;

hanna.tolonen@hus.fi

\section{ABSTRACT}

Objectives To explore relevant Finnish stakeholders' perceptions on the automatic substitution of biological medicines with particular focus on medication safety and issues that need to be considered to create an appropriate model for automatic biological product substitution.

Design Qualitative interview study.

Methods Data were collected in semistructured individual $(n=17)$, pair $(n=7)$ and group $(n=8)$ interviews (32 interviews, 62 participants) in 2018. Participants represented a wide range of stakeholders involved in the pharmacotherapy process: community pharmacists ( $n=8$ interviews), authorities $(n=7)$, prescribers $(n=7)$, pharmaceutical industry and wholesalers $(n=6)$, patients/ customers $(n=2)$, hospital pharmacists $(n=1)$ and nurses $(n=1)$. Inductive content analysis was performed. Results Benefits of automatic substitution were identified as cost savings, more patients receiving biological treatments and enhanced continuity of treatment. Six major risk categories were identified: (1) the patient's medication is interrupted or complicated temporarily or permanently, (2) the patient uses two products with the same active substance, (3) the traceability of the product is compromised, (4) the patient cannot get into healthcare in case of problems, (5) the patient does not receive substitution-related advice from a pharmacy and (6) the patient is distracted by the support material he/she receives. Several risk mitigation measures were commonly mentioned: medication and device counselling by pharmacists $(n=23)$, infrequent substitution interval $(n=15)$ and better knowledge on biosimilars among healthcare providers $(n=13)$.

Conclusion Automatic substitution of biologics is associated with risks that should be prospectively managed before implementing the procedure. The substitution also introduces new tasks and communication needs to those involved in actual medication use process, particularly to community pharmacists who will be responsible for substitution and counselling the patients.

\section{INTRODUCTION}

Biological medicines ('biologics'), especially therapeutic proteins, are used to treat an increasing number of patients over a wide range of therapeutic indications. ${ }^{1}$ The high

\section{Strengths and limitations of this study}

- This is the first study to explore potential medication safety risks while implementing automatic substitution of biologics.

- Interviews are an effective method to gain an indepth understanding of important issues when considering a model for automatic substitution of biologics.

- A wide range of stakeholders participated in the interviews offering their viewpoints.

- This study explored varying stakeholder views on automatic substitution of biologics rather than compared differences between the stakeholder groups.

- The limited number of patients and nurses in the interviews may have influenced the results.

costs of original biological medicines represent a major burden on healthcare budgets. ${ }^{2}$ The biosimilar concept with abbreviated approval pathway was developed in the European Union (EU) to increase competition within biologics' market. ${ }^{3}$ Subsequently, biosimilars have triggered price competition and price reductions in several countries. ${ }^{4}$ In Finland, hospitals have generally adopted biosimilars into their formularies mainly through their tendering processes. ${ }^{45}$ However, in ambulatory care, the uptake of biosimilars has been poor. ${ }^{6}$ In ambulatory care, the decision to switch between biologics is made by the prescriber and the incentives to switch from a biologic reference product to a biosimilar are weak: the social insurance reimbursement system covers the majority of expenses for the patient either way. ${ }^{5}$

The introduction of automatic generic substitution was an effective way to restrict the increase of medication expenditures when uptake of generic prescribing lagged..$^{7-10}$ From a regulatory perspective, the approaches to demonstrate equivalence of generic small 
molecule drugs and biosimilars are analogous; however, the requirements to demonstrate the similarity are more extensive for biosimilars. ${ }^{11}$ This is due to the heterogeneity of the molecules produced by biotechnological processes. ${ }^{12}$ Theoretical considerations and clinical switching studies suggest that biosimilars developed according to the EU guidance are interchangeable with their reference products. ${ }^{13-20}$ Furthermore, no consistent safety signals from pharmacovigilance reporting systems that monitor switching between highly similar biologics have been identified. ${ }^{1221}$

Several prominent EU regulatory agencies, including Finnish Medicines Agency, and medical societies have issued position papers supporting the interchangeability of biosimilars with their reference products under the supervision of the prescriber. ${ }^{22}$ However, since the marketing authorisation process ensures that the biosimilar has the same efficacy and safety profile as the reference product, relevant changes in treatment are not expected on switching. ${ }^{13}$ Thus, in countries where biosimilars have been regarded as interchangeable, the (automatic) substitution is no longer a scientific question, but a political, practical and organisational issue. The aim of this study was to explore relevant Finnish stakeholders' perceptions on the automatic substitution of biological medicines with the focus on medication safety. In the spirit of prospective risk management, our focus was to identify issues that should be considered to create an appropriate model for automatic substitution of biological medicine.

\section{METHODS}

Finnish stakeholders' perceptions on automatic substitution of biologics were explored by semistructured theme interviews. This method is particularly suitable for situations where it is desirable to elicit a wide range of views on a specific topic. ${ }^{23}$ The theme interview is also well suited for previously unstudied topics. ${ }^{24}$

\section{Interview guide and additional interview material}

The flexible interview guide with four themes was developed (online supplement material 1). The flexibility in the guide allowed a conversational and interactive approach in the interviews. ${ }^{23}$ The themes were: (1) attitudes towards automatic substitution, (2) medication safety on substitution, (3) prerequisites for implementation and specific issues pertaining to different perspectives and (4) implementation and monitoring. The interview guide was constructed based on the study aim, and the research group's experience and knowledge that covered, for example, biosimilar policy making on the EU level, implementing the generic substitution at the national level as well as extensive medication safety research. In the interviews, a table of biosimilars that were on the market in Finland in August 2018, and a table of biosimilars authorised in the EU, but not launched in Finland were made available.
The interview guide was tested in a pilot interview. Based on the pilot, the explanations of the key terms used in the interview were added to the interview material. After this, the guide was adapted but kept open to further adjustments during the data collection, particularly regarding different stakeholder roles. The pilot interview was included in the research data.

\section{Sampling and recruitment of the interviewees}

The study sample covered a full range of national stakeholders associated with biological medication starting from the marketing authorisation to medicine distribution and patient care (online supplement material 2). The research group identified the stakeholders that were invited to participate. Purposive sampling was used to select the stakeholders to ensure the coverage of all relevant perspectives. ${ }^{25}$ The following operators were included: community and hospital pharmacists, prescribers, nurses, patients/customers, pharmaceutical industry, pharmaceutical wholesalers and different authorities regarding distribution and pharmacotherapy process.

Interviewees were primary recruited through interest groups, professional associations and patient organisations. The aim of the interviews was to obtain rich and comprehensive insights from interviewees. The chosen organisations were contacted by email. The date and time for the interview were agreed by email or telephone. The invited organisations independently nominated the person or persons to participate in the interview. This influenced whether the interview was conducted as an individual, pair or group interview. Direct recruits were made in situations where it was appropriate (eg, authorities). A total of 38 interview invitations were sent.

\section{Data collection}

Written informed consent was obtained from all interviewees. The interviews were audio recorded. The interviews were conducted by HMT (female pharmacist, MSc, with training in qualitative interviews) in Finnish at places that were easily reached by the interviewees and were sufficiently private to facilitate a free and confidential exchange of information.

At the beginning of each interview, the interviewer went through the most important terms (biosimilar, substitution and medication safety) used in the interview to ensure that the concept would not cause any misunderstandings. Interviewees were encouraged to share their personal views and the possible positions of their background organisation on the topic.

\section{Data analysis}

Audio records were transcribed verbatim by a professional transcriber and transcripts were checked for accuracy by one researcher (HMT). The identities of the participants were anonymized prior to data analysis. Inductive content analysis, which is applicable for research topics which are not well-known and are expected to yield new insights, 
was used. ${ }^{26}$ Data from individual, pair and group interviews were analysed in the same way, using the interview as the level of the analysis rather than analysing views of each individual participants. The data were read through several times and sentences relevant to research question were coded. Codes that had the same or similar meaning were combined. Combined codes were grouped into subcategories and further categories that formed, for example, perceived risk descriptions that were presented in a conceptual model. Suitability of the interchangeability for the biologics, as it is recognised in Finland, was not in the focus. The data were mainly analysed by one researcher (HMT). There were several sessions with the research group where data, analysis and preliminary results were discussed to improve the trustworthiness of the qualitative analysis. The most representative quotations were reported. A checklist of the consolidated criteria for reporting qualitative studies was utilised when applicable. ${ }^{28}$

\section{Ethical approval}

The interviews were conducted in accordance with the Finnish National Board of Research Integrity guidelines for the ethical principles to conduct a research. ${ }^{29}$ Ethical pre-evaluation was not required, as all interviewees were asked for informed consent, only adults participated in the interviews and the interviews did not cover the interviewees' personal health information.

\section{Patient and public involvement}

The patients participated in the study as representatives of their patient organisations. There was no patient or public involvement in the planning phase or design of the study. The study participants, including patient representatives, will be personally informed of the main results of the study.

\section{RESULTS}

\section{Study participants}

A total of 32 interviews with 62 participants were performed between August and November 2018 (table 1). There were 17 individual interviews. The rest were either pair $(n=7)$ or group $(n=8)$ interviews. Each pair and group interview included participants only from one stakeholder group. The mean duration of the interviews was $55 \mathrm{~min}$ (range from 30 to $98 \mathrm{~min}$ ). All interviews were conducted face-to-face. In three interviews, there were additional participants $(n=4)$ also via Skype or over telephone.

Most of the contacted organisations and individuals agreed to participate in the study $(\mathrm{n}=32,84 \%)$. Six contacts did not lead to an interview. Three invited stakeholders refused to participate due to lack of knowledge or experience on the topic and two participants dropped out since a suitable interview time was not found (group interviews). No response was received for one invitation.
Table 1 Number of interviews $(n=32)$ and background of the interviewees $(n=62)$

\begin{tabular}{ll}
\hline Background of the interviewees & $\begin{array}{l}\text { Number of } \\
\text { interviews (number } \\
\text { of interviewees) }\end{array}$ \\
\hline $\begin{array}{l}\text { Community pharmacists } \\
\text { National and/or local professional } \\
\text { associations }\end{array}$ & $8(15)$ \\
Practitioners (pharmacy owners, \\
pharmacists; MSc and BSc)
\end{tabular}

A summary of the characteristics of the participants is given in table 1.

\section{General perceptions of biological medicines' substitution}

Practically, all participants in the interviews $(n=32)$ preferred physician-led switching as a primary method for enhancing the use of biosimilars, whereas varied attitudes regarding automatic substitution of biologics in community pharmacies was elicited. In half of the interviews $(n=16)$, the position of the attendees was positive to the substitution at the pharmacy level. In $25 \%$ of the interviews $(n=8)$, interviewees suggested that there is not enough experience on biosimilars, and they saw risks that should be solved prior to initiating automatic substitution in pharmacies. Automatic substitution of biologics was deemed as a totally inappropriate model in some interviews $(n=8)$. Some negative comments reflected distrust on quality, safety and efficacy of biosimilars in general. Positive and negative attitudes were both found among all stakeholders, including patient representatives, and all types of interviews (individual, pair or group interviews). Treatment-naive patients were perceived to be the most suitable for substitution.

\section{Benefits of the automatic substitution of biologics}

In addition to cost-savings in healthcare $(n=17)$, the stakeholders identified several other benefits that might 
Table 2 Potential benefits of substitution at the pharmacy level as identified in the interviews $(n=32)$

\begin{tabular}{lll}
\hline Benefit & Description of the benefit & Citation from the interview \\
\hline Savings & Society saves on drug costs $(n=17)$ & '... that's where the big money can be saved' \\
& & PRESCRIBER06
\end{tabular}

More Lower prices can improve patients' willingness and

patients ability to use self-injectable biological products

can receive $(n=5)$

treatments

'... patient's involvement in the treatment may be better if he/she gets a cheaper medicine, it is a bit of problem with expensive biological drugs before reaching annual limit for co-payment...' NURSE01

Patients have better access to biological treatments
$(n=5)$

...lower prices may allow more people to receive treatment...' PATIENT04

Patients may start biological treatment earlier $(n=3) \quad$ '... maybe one should not focus only on savings here but just how you can treat patients at an earlier stage...' INDUSTRY05

New drug treatments can be introduced without compromising sustainability of pharmacotherapy $(n=2)$

'.. with the savings these innovative medicines can be offered to more patients...' PHARMACIST08

Continuity of Treatment can continue smoothly with another treatments product if there is a medicine shortage $(n=4)$

'... if they were in a kind of generic substitution, there would more tools for these disruptions.' PHARMACIST05

Decreasing prices can increase the pharmacy's willingness to keep the products in stock $(n=2)$

'And, of course, depending on which price category the product is, if it is always available in the pharmacy as for example insulin, as soon as patient gets his medicine, he can start using it immediately.' PHARMACIST01

Patients may receive a 3-month dose of reimbursed medication at the same time if the price of the product falls sufficiently $(n=1)$

'So if that price dropped so much that the customer would get it (dispensed medicine) more to take with, and on the other hand it would be a good thing for the customer not to visit pharmacy every month ...' PHARMACIST14

Treatment can continue smoothly with another reimbursed product if there is a change in the reimbursement status of the patient's current medicine brand $(n=1)$

'But even in this situation (the original product is not reimbursed any more) if you speculate that there is a drug substitution and you can switch directly to the biosimilar, so this recipe 'exchange rally' is much smaller.' PHARMACIST01

Automatic substitution could improve immediate '...for example, in this Neupogen case, you should keep availability if pharmacies were aware of the product that has to be dispensed $(n=1)$ four different products in stock when you don't know what the doctor prescribes, but with the substitution you only need one product to start the treatment...' AUTHORITY18

be achieved with implementing biologics' substitution (table 2). More patients can receive treatments, if savings result in increased number of patients on biological treatment $(n=5)$, initiation of biological treatment in earlier phase $(n=3)$ or introduction of novel treatments for new patients $(n=2)$. Substantial price reductions may also increase patients' willingness and ability to use biologics $(n=5)$, if the price reductions are substantial. Continuity of treatment was also identified as a potential benefit, for example, in the case of medicine shortages $(n=4)$.

\section{The perceived medication safety risks and their management}

Most of the risks with biologics' substitution identified in the interviews were related to the interruption or complication of patient's pharmacotherapy because of issues such as inadequate knowledge of the administration device $(n=19)$, medicine availability problems $(n=12)$ or patient's distrust to the biosimilar medicine itself $(\mathrm{n}=11)$ (table 3). For example, differences in packages and complex naming $(\mathrm{n}=11)$ can introduce a risk for duplicate therapy. Traceability of the dispensed product name and batch number (due to long-term side effects; $\mathrm{n}=8$, or unavailability of the dispensed product name or batch number; $n=5$ ) and insufficient availability of healthcare contacts $(\mathrm{n}=12)$ were also identified as medication safety risks in substitution in several comments. Lack of appropriate training for patients in the pharmacy and the inconsistencies between the pharmaceutical product-specific patient information materials were mentioned as risks in some interviews.

Several methods to minimise medication safety risks were proposed in the interviews. Medication and device counselling provided by pharmacists $(n=23)$, infrequent substitution interval $(\mathrm{n}=15)$ and better knowledge on biosimilars among healthcare providers $(n=13)$ were identified as potential remedies in multiple interviews.

\section{Substitution frequency}

The interviewees were asked about optimal substitution interval for biologics. Only three interviewees agreed that the current generic substitution interval of 3 months (eg, how often the medicine could be substituted in the 
Table 3 Perceived medication safety risks and their management measures as identified in the interviews ( $n=32)^{*}$

\section{Potential risk \\ Descriptions of perceived risks with manifestation}

The patient's medication is The patient does not know how or is unable to use the interrupted or complicated administration device correctly $(n=19)$

temporarily or permanently $>$ The patient feels that the new administration device is difficult to use

- Patient fails to administer medicine or he/she is not able to repeat administration

- New administration device is not suitable for the patient (handicap, visual impairment)

Too wide a range of different devices is available

The medicine is not available at the right time $(n=12)$

- The pharmacy does not have the product in stock

There is a medicine shortage

The patient does not trust the new medicine $(n=11)$

- The patient has benefited significantly from the original product and does not want to change

- The patient receives conflicting messages from different healthcare professionals

- The substitution will surprise the patient at the pharmacy

- Patient is suspicious due to different product appearance and trade names

The patient experiences adverse reactions after substitution $(n=11)$

- Reactions to excipients

- Nocebo-effect

- Large-scale substitution may reveal problems that were not previously detected

Concern about losing the medicine's effectiveness $(n=8)$

- The development of drug antibodies is accelerated by repetitive switches

There is no large-scale experience on repetitive switches

The patient uses two products with the same active substance

\section{The traceability of the} product is compromised
Based on the appearance or name of the product, it is not possible to determine whether the active substance is the same $(n=11)$

- Different appearance of packages

- Different trade names

- Generic names can be confusing

- Patient recognises only the established brand name

The patient does not understand that substitution has taken place $(n=8)$

- Patients with polypharmacy, the elderly, patients with impaired cognition

The patient has two prescriptions for the same active substance $(\mathbf{n}=3)$

- The patient has a prescription for the original product and another prescription for the biosimilar

The biological drug can have long-term side effects $(n=8)$

The product that caused a side effect cannot be traced

In case of a side effect, the product cannot be traced $(n=5)$

- The physician is not aware of what brand and what batch the patient has used

Patient refers only to the originator's brand name
Methods to minimise risk as identified in the interviews $(n=32)$

- Pharmacy provides medication counselling including device counselling with optional injection training $(n=23)$

- The interval† between substitutions should be longer for biological drugs than for generic medicines $(n=15)$

- Further training of healthcare professionals on biosimilars $(n=13)$

- Consistent, positive attitude towards substitution across healthcare and pharmacies $(n=9)$

- A motivating conversation with the patient by a doctor and nurse $(n=8)$

- Ensuring at every pharmacy and healthcare visit that the patient can use the device correctly $(n=8)$

Medication monitoring $(\mathrm{n}=8)$

- The patient knows where to contact in case of problems $(n=7)$

- Prescriber can prohibit substitution if necessary $(n=7)$

- Evaluation of the interchangeability of devices in a regulatory process $(n=6)$

- Dispensing of biologics based on an appointment or pre-order $(\mathrm{n}=6)$

- Switches and substitution are avoided if medication has not been stabilised $(n=6)$

- Evaluation of biological medicines suitable for substitution by the regulatory authority $(n=6)$

- Postmarketing surveillance of medicines $(n=5)$

- Regional co-ordination/co-operation between healthcare and pharmacies $(n=4)$

Substitution policy prevents shortages by supporting pharmaceutical companies to anticipate the market $(n=3)$

- Mandatory reserve supplies of biological medicines $(n=2)$

- Providing reliable drug information sources for the patient $(n=2)$

Demonstrating administration devices in drug counselling (visuality) $(n=9)$

- Prescriber can prohibit substitution $(n=7)$

- Printing drug lists and checking medication $(n=1)$

- The new product is marked with a label that indicates the substitution $(n=1)$

- The new product is not delivered too early, so the patient does not have two products at the same time at home $(n=1)$

- Pharmacist invalidates the previous prescription when substituting $(n=1)$ 
Table 3 Continued

\begin{tabular}{ll} 
Potential risk & Descriptions of perceived risks with manifestation \\
\hline $\begin{array}{l}\text { The patient cannot get } \\
\text { into healthcare in case of }\end{array}$ & Healthcare is overloaded due to substitution $(\mathbf{n}=12)$ \\
problems & Substitution increases patient contact with healthcare \\
& Patients with substituted medicine would be in closer \\
follow-up. The patient contacts the physician to obtain a \\
substitution refusal
\end{tabular}

The patient does not receive substitutionrelated advice from a pharmacy

\section{The patient is distracted} by the support material he receives

'On behalf of the patient' customers $(n=5)$ of a patient

- The patient can apply for a medicine from the 'smart box' when convenient

There may be differences in written material received by the patient $(n=2)$

- Material for various products is accumulated

Methods to minimise risk as identified in the interviews $(n=32)$

- Further training of healthcare professionals on biosimilars $(n=13)$

- Consistent, positive attitude towards substitution across healthcare and various pharmacies $(n=9)$

- A motivating conversation with the patient by a doctor and nurse $(n=8)$

- For example, a relative can apply for a medicine on behalf

- Medication counselling with both visual and written material $(n=7)$

- Prescriber can prohibit substitution $(n=7)$

New methods to dispense medicines $(n=1)$

The availability of additional materials may vary by product

$(n=2)$

- Pharmaceutical company supplies additional productspecific material such as web pages, storage and shipping boxes

*Please note, 'patient perspective' can be either patient representative's view or other stakeholder representative's assumption on patient's view. †In Finland, the substitution interval for generic small molecules (generic substitution interval), eg, how often patient's medicine could be substituted at the pharmacy, is related to the reference price that establish the reimbursement level and is confirmed quarterly (reference price interval) (The Social Insurance Institution of Finland. Generic substitution and the reference price system. Available: https://www.kela.fi/web/en/medicine-expenses-generic-substitution-and-thereference-price-system(accessed June 2019)).

pharmacy $^{5}$ ) would be suitable for biologics and none recommended to have an interval of 1 month. The most popular interval for substitution was 12-24 months $(n=13)$. In some interviews, the participants did not want to mention any precise frequency but mentioned that it 'should be done rarely'. Both the validity period of a prescription and the adjusted reference price intervals for biologics were suggested to determine the interval of biologics' substitution.

Participants suggested an association between substitution frequency and medication safety and pharmaceutical market attractiveness (table 4 ). It was suggested that a long substitution interval may increase medication safety compared with shorter intervals. On the contrary, pharmaceutical companies' interest to enter local pharmaceutical market may be compromised if the substitution interval is too long.

\section{Tasks and responsibilities of the patients and healthcare professionals}

Automatic substitution was predicted to bring new tasks to community pharmacists (figure 1). Lack of information sharing between community pharmacists and nurses who are involved in patient counselling was noted in

Table 4 Influence of the substitution frequency on medication safety and attractiveness of the pharmaceutical market in Finland emphasised in the stakeholders' interviews $(n=32)$

\begin{tabular}{|c|c|c|}
\hline & Short substitution interval & Long substitution interval \\
\hline Medication safety & $\begin{array}{l}\text { Positive impact on } \\
\text { Continuation of treatment in case of shortages } \\
\text { of a particular product } \\
\text { Negative impact on } \\
\text { Device expertise of the patient } \\
\text { Traceability of the product and batch number } \\
\text { Management of support material for the } \\
\text { patient }\end{array}$ & $\begin{array}{l}\text { Positive impact on } \\
\text { Device expertise of the patient } \\
\text { Traceability of the product and batch } \\
\text { number } \\
\text { Management of additional patient } \\
\text { material } \\
\text { Negative impact on } \\
\text { Continuity of treatment in case of } \\
\text { shortages }\end{array}$ \\
\hline $\begin{array}{l}\text { Attractiveness of } \\
\text { pharmaceutical market }\end{array}$ & $\begin{array}{l}\text { Negative impact on } \\
\text { Predictability of pharmaceutical market } \\
\text { Stock management in pharmacies } \\
\text { Uncertain impact on } \\
\text { Competition between products }\end{array}$ & $\begin{array}{l}\text { Positive impact on } \\
\text { Predictability of pharmaceutical market } \\
\text { Stock management in pharmacies } \\
\text { Negative impact on } \\
\text { Competition between products (prevents } \\
\text { rapid reaction to price changes) }\end{array}$ \\
\hline
\end{tabular}




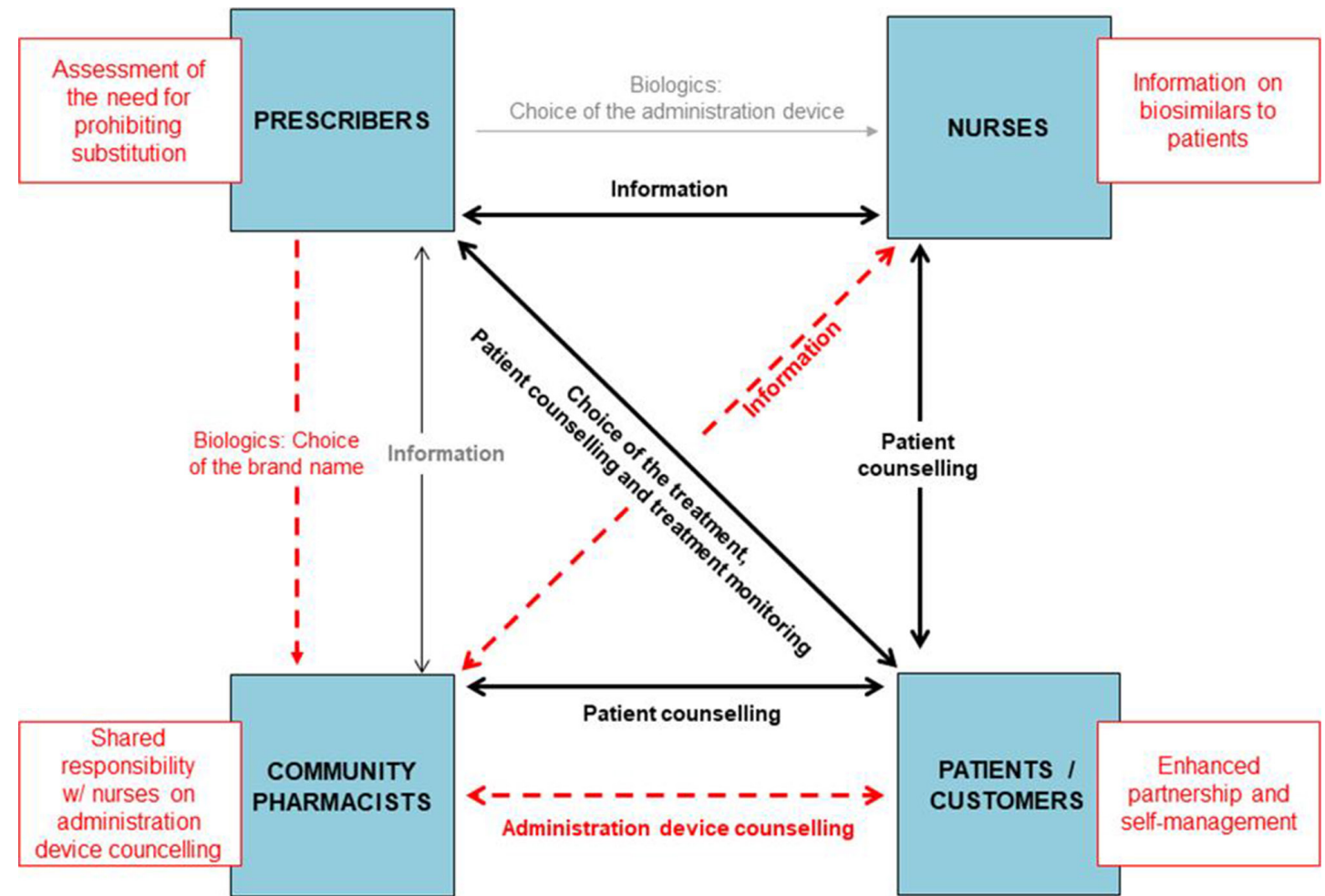

Figure 1 Existing interactions (black lines) between patients and healthcare professionals in biological medicine treatment in Finland and new tasks (red boxes) and new interactions (red dashed lines) between patients and healthcare professionals induced by automated substitution of biologics identified in the stakeholders' interviews $(n=32)$.

several interviews. It was highlighted by interviewees that this information pathway should be developed for effective and consistent counselling on administration devices for patients. Multiple interviewees stated that collaboration between teams in healthcare and pharmacies should be improved before introducing automatic substitution of biologics. On the contrary, patients' role as a partner was discussed by the various interviewees.

\section{DISCUSSION}

The stakeholders had a generally positive attitude to the biologics' substitution at the pharmacy level. Treatment-naive patients were regarded as the most suitable targets for substitution. The stakeholders identified several benefits and risks related to automatic substitution of biologics. Many of the risks that were identified in the interviews are applicable also to generic substitution, such as patients' expected distrust towards a new medicine and a parallel use of the same active ingredients in different products (table 3). Traceability of the dispensed product name and batch number, and patients' knowledge and training for a new administration device were identified as risks that are not shared with generic substitution. On the contrary, multiple mitigation measures against medication safety hazards were also identified, such as infrequent substitution interval, improved knowledge of biosimilars among healthcare personnel and administration device counselling at pharmacies. These measures can allocate some new tasks to community pharmacists.

\section{Education of healthcare providers and patient counselling}

Our study indicates that the personnel in healthcare units and community pharmacies need substantial detailed information on biosimilars, which is consistent to previous findings. ${ }^{30-32}$ The outcome of automatic substitution may be negatively influenced if the provided information is ambiguous or not sufficiently detailed. ${ }^{33}$ The attitudes of the prescriber or other providers towards substitution have been shown to have an impact on the patient's acceptance to switch medicine and the perceived outcome of the switch. ${ }^{3455}$ In generic substitution, lack of appropriate information has been shown to be confusing and raise doubts regarding the quality, safety and efficacy of the generic product. ${ }^{36-38}$

Regarding the experience of generic substitution, it is important to provide consistent information to patients about biosimilars, the reasons for the switch and the product in question. Based on the assessment by the regulatory authorities, the marketing authorisation holder may be required to produce risk minimisation material, such as patient 'alert cards' used to manage the adequate monitoring of treatment. ${ }^{39}$ In general, the risk minimisation material of biosimilars should be consistent with the information of the reference product. In order to avoid confusion among patients, these materials should be as harmonised as possible. ${ }^{39}$

Our study identified potentially new roles for community pharmacists to facilitate safe and effective substitution of biologics. In Finland, the patient counselling on 
any biological medicine is usually given by the prescribers and nurses. Community pharmacists are obligated by law to ensure that the patients know the appropriate use of medicinal products, including administration devices. ${ }^{40}$ Thus, all suggested new roles are already within the current mandate of the Finnish pharmacies. Nevertheless, it seems that introducing the substitution of biologics would require a major effort to educate and train pharmacy staff in dealing with biologics and their administration devices as well as in patient counselling. General information on biosimilars and their interchangeability is available in local languages and can be tailored to the needs of the pharmacies. ${ }^{41}$ Ideally, pharmacies and local healthcare units should collaborate in developing patient counselling materials and techniques in order to increase synergy and to avoid overlapping work.

\section{Administration devices}

According to our findings, patient's knowledge of use of the administration devices is one of the key factors to the success of substitution. The different administration devices can present an obstacle to switching. ${ }^{42}$ However, all administration devices for biosimilars and their reference products have been tested for usability at the time of marketing authorisation. ${ }^{43}$ Still, there may be clinically relevant differences in the usability of different devices, as experienced by the patient. Thus, to assure safe substitution, the national authority will need to assess the suitability of administration devices for substitution in all relevant patient groups. For instance, substitution may involve the use of a different type of device, such as an autoinjector instead of a prefilled syringe. The risk for clinically relevant problems when using different administration devices can be minimised with adequate patient counselling, including device training, and good communication within medication management team (figure 1). The pharmacy staff should be able to provide the necessary device training if the patient or caregiver is unfamiliar with the new device in order to ensure the appropriate administration of the product.

\section{'Dispense as written'}

According to previous studies, physicians have reservations regarding automatic substitution. ${ }^{4-49}$ Some physicians seem to be hesitant to accept automatic substitution of biologics because of the perceived limitation of the physician's autonomy. ${ }^{46} 50$ This was also identified in recent Finnish study. ${ }^{51}$ This view can be challenged, since substitution of biosimilars, like generic substitution, deals with therapeutically equivalent products. The need for automatic substitution is driven by insufficient cost consciousness of prescribers who are major players in the channelling of public funds. ${ }^{52}$

Nevertheless, there may be situations in which substitution is not appropriate. According to the local legislation, the prescribers can prohibit generic substitution by writing the prescription with a 'dispense as written' designation. ${ }^{3453} 54$ The interviewees in our study suggested that this may also be necessary in substitution of biologics. For instance, the patient may not have reached an optimal treatment response with the present medicinal product. In this case, substitution needs to be postponed until a rational decision can be made either to substitute or to prescribe a product with a different active substance. Substitution may also be inappropriate if the patient will not be able to use the new product due to physical handicap or other relevant reasons. Nevertheless, the patients and healthcare providers may also consider a new device as easier to use. ${ }^{55-57}$ It is important that the physicians will have to present a clinically sound justification if they wish to prohibit the substitution.

\section{Substitution interval}

One of the concerns related to substitution was related to the frequency of switches. The stakeholders seemed to favour longer switching intervals for practical and safety reasons. Frequent switching could overload the pharmacies in patient counselling and increase the risk of medication errors and potential switch-related adverse effects, such as nocebo effect. Multiple switches may also confuse patients and their caregivers. ${ }^{42}$ Troubleshooting may also be difficult in cases of frequent switching and adverse effects with long latency, such as immunogenicity and loss of efficacy. A long switching interval may also increase the predictability of the market and simplify the logistics and the management of the stock in the pharmacies, especially for expensive biologics with limited shelflife. Thus, the optimal substitution interval for biologics should be determined by several factors, both theoretical and practical.

\section{Traceability}

Traceability has been presented as a problem of biosimilar uptake, especially on substitution. ${ }^{58}$ In contrast to general perception, traceability of biosimilars and their reference products has been shown to be adequate. ${ }^{59}$ The main challenge in traceability of all biologics is the poor reporting of the batch numbers by healthcare personnel. In contrast, the pharmacies in Finland are already obligated to record the batch numbers of all dispensed biological medicines. ${ }^{60}$ Thus, there is a good argument that traceability would be optimised at the pharmacy level. One issue that needs to be overcome, however, is that this information is not automatically transferred to patient records. Nonetheless in Finland, it is possible for a prescriber to find the brand name of the dispensed medicine in the electronic archive of prescriptions. ${ }^{61}$ Similar helpful IT systems may be available or in development in other countries. In addition, traceability will be further improved in the $\mathrm{EU}$ by the recently introduced unique identifiers of all packages of prescribed medicinal products. ${ }^{62}$ Nevertheless, the information flow between the healthcare units and the community pharmacies should be improved.

\section{Practical and policy implications}

The marketing authorisation of biosimilar therapeutic proteins is based on the recommendation of the European 
Medicines Agency and granted by the European Commission, whereas the interchangeability and substitutability are under responsibility of EU member states. ${ }^{63}$ Thus, each member state has to develop its own procedures to assess interchangeability. For example, in Finland, automatic substitution of generics is assessed for each new product entering the market. ${ }^{64} \mathrm{~A}$ separate assessment of substitutability needs to be done in EU member states for every new biosimilar as well if substitution is pursued. This assessment should include the dosage forms, administration devices and available product information. Instead, in the USA, interchangeability of biologics is considered as an extension of the biosimilar status including additional clinical switching studies. ${ }^{65}$ In states where legislation allows, pharmacist can substitute products with interchangeability status. ${ }^{6566}$ Substitution is allowed in some other countries, for example, in France and Australia. ${ }^{67}$ Despite the legal basis, clear guidance for substitution practice and patient counselling is needed. ${ }^{68}$

Small price difference between reference product and biosimilar is not encouraging physicians to switch. ${ }^{51}$ However, substitution between the reference products and their biosimilars may be crucial not only for savings and price competition but also for practical and logistical reasons of limiting the number of products that must be stocked in the pharmacy. ${ }^{66}$

\section{Need for further research}

Considering substitution in practice, it may be appropriate to pilot the chosen model for substitution before adopting the policy in full-scale. Practical, safety and economical aspects should be monitored and studied during the pilot phase in order to obtain comprehensive understanding of substantial benefits and risks as well as market dynamics associated with implementing substitution for biologics.

This study pointed out that pharmacist-provided patient counselling is an important factor to ensure the medication safety in biologics' substitution. Despite the emerging biologic substitution experience in some countries, the content of the information that community pharmacists should provide to the patients and caregivers has not been studied nor reported. ${ }^{67-69}$ Especially, studies exploring patient perspective to biologics' automatic substitution are needed.

\section{Limitations of the study}

Although a wide range of stakeholders participated in the interviews, the community pharmacists and authorities constituted the majority of the participants. The limited number of patients and nurses compared with other stakeholder representatives may have skewed the results. This may have been partially compensated by the views expressed by non-patients as "patient perceptions'. However, there is often a difference between what patients actually think and what healthcare professionals believe patients to think.
The views of different professions were grouped together. This was because the aim of this study was to explore views from different stakeholders to build up a model for automatic substitution of biologics rather than to compare differences in opinions between stakeholder groups. We intentionally merged individual and pair/ group interviews because the stakeholders nominated a varying number of representatives to be interviewed. In each interview, the participants represented only one stakeholder group, which might have mitigated differences in dynamics of these approaches. The challenge to combine these two methods led to the decision to analyse the data on the level of the interviews, not by each interviewee.

Finally, similar to all qualitative research, it is not possible to fully remove researcher bias. It should be noted that the results reflect the local circumstances in Finland and may not as such be applicable to other EU countries. However, the majority of issues covered here are common to many European healthcare systems.

\section{CONCLUSION}

Perceptions of the stakeholders on automatic substitution for biologics at the pharmacy level were more positive than in previous studies. Several reservations were presented, and risk mitigation measures were deemed necessary.

The identified medication safety risks can be mitigated by an appropriate substitution model developed in collaboration with relevant stakeholders and piloted in pharmacies. Each biosimilar product should be assessed for the critical factors, such as relevant product information (in relation to substitution), presentations and administration devices. The substitution also introduces new tasks and communication needs to those involved in actual medication use process, particularly to community pharmacists who will be responsible for substitution and counselling the patients. Electronic systems, such as electronic prescribing, pharmacy IT systems and unique identifiers of packages, are helpful for traceability. Consistent and unbiased information should be made available to all substitution stakeholders. The clinical and economical outcomes of substitution should be monitored after institution of routine substitution.

\section{Author affiliations}

${ }^{1}$ Clinical Pharmacy Group, Division of Pharmacology and Pharmacotherapy, Faculty of Pharmacy, University of Helsinki, Helsinki, Finland

${ }^{2}$ HUS Pharmacy, Helsinki University Hospital, Helsinki, Finland

${ }^{3}$ Finnish Medicines Agency Fimea, Helsinki, Finland

${ }^{4}$ Center for Medication Quality and Outcomes, The Johns Hopkins Health System, Baltimore, Maryland, USA

${ }^{5}$ Center for Drug Safety and Effectiveness, The Johns Hopkins Bloomberg School of Public Health, Baltimore, Maryland, USA

${ }^{6}$ University of Helsinki, Helsinki, Finland

Acknowledgements We thank all the participants in the interviews. We would also like to warmly thank the project group in Finnish Medicines Agency Fimea. 
Contributors HMT, MSAA, PR, KH-A and PK contributed to the conception or study design. HMT was principal investigator to acquire and analyse the data, and draft the manuscript. All authors (HMT, MSAA, PR, KH-A, KMS and PK) participated in interpretation of the data and critical revision of the manuscript. All authors approved the final version.

Funding This work was funded by Finnish Medicines Agency Fimea and supported by University Pharmacy, Helsinki, grant.

Competing interests HMT has participated in a congress for which participation fee was sponsored by Roche $\mathrm{Oy}$.

Patient consent for publication Not required.

Provenance and peer review Not commissioned; externally peer reviewed.

Data availability statement All requests should be directed to the corresponding author.

Open access This is an open access article distributed in accordance with the Creative Commons Attribution Non Commercial (CC BY-NC 4.0) license, which permits others to distribute, remix, adapt, build upon this work non-commercially, and license their derivative works on different terms, provided the original work is properly cited, appropriate credit is given, any changes made indicated, and the use is non-commercial. See: http://creativecommons.org/licenses/by-nc/4.0/.

ORCID iD

Hanna M Tolonen http://orcid.org/0000-0002-6824-7566

\section{REFERENCES}

1 European Commission, DG Enterprise and industry. What you need to know about biosimilar medicinal products. Process on corporate responsibility in the field of pharmaceuticals access to medicines in Europe. A consensus information document, 2013. Available: https://ec.europa.eu/docsroom/documents/8242/attachments/1/ translations/en/renditions/pdf [Accessed Apr 2019].

2. Blackstone EA, Fuhr JP. The economics of biosimilars. Am Health Drug Benefits 2013;6:469-78.

3 European Medicines Agency. Guideline on similar biological medicinal products CHMP/437/04 Rev 1, 2014. Available: https:// www.ema.europa.eu/documents/scientific-guideline/guidelinesimilar-biological-medicinal-products-rev1_en.pdf [Accessed Dec 2018].

4 IQVIA. The impact of Biosimilar competition in Europe, 2018. Available: https://ec.europa.eu/docsroom/documents/31642 [Accessed Apr 2019].

5 Finnish Medicines Agency and Social Insurance Institution. Finnish statistics on medicine, 2017. Available: http://urn.fi/URN:NBN:fife2018112148808 [Accessed Apr 2019].

6 Ruokoniemi P. Rational prescribing, dispensing and use of medicines in current and future healthcare and social welfare structures. reports and Memorandums of the Ministry of social Affairs and health 12/2018. Helsinki: Ministry of Social Affairs and Health, 2018.

7 Mansilla C, Cárdenas J, Kaplan WA, et al. Evaluation of the effects of a generic substitution policy implemented in Chile. BMJ Glob Health 2019;2:e000922.

8 Aalto-Setälä V. The impact of generic substitution on price competition in Finland. Eur J Health Econ 2008;9:185-91.

9 Andersson K, Sonesson C, Petzold M, et al. What are the obstacles to generic substitution? An assessment of the behaviour of prescribers, patients and pharmacies during the first year of generic substitution in Sweden. Pharmacoepidemiol Drug Saf 2005;14:341-8.

10 Stadhouders N, Kruse F, Tanke M, et al. Effective healthcare cost-containment policies: a systematic review. Health Policy 2019;123:71-9.

11 van der Plas RM, Jongen PMJM, van Zwieten-Boot BJ, et al. The EU regulatory approach to generics and biosimilars is essentially similar. GaBl J 2015;4:9-10.

12 European Medicines Agency and European Commission. Biosimilars in the EU. Information guide for healthcare professionals. European Medicines Agency 2017 https://www.ema.europa.eu/en/documents/ leaflet/biosimilars-eu-information-guide-healthcare-professionals_en. pdf (accessed Apr 2019).

13 Kurki P, van Aerts L, Wolff-Holz E, et al. Interchangeability of biosimilars: a European perspective. BioDrugs 2017;31:83-91.

14 Cohen HP, Blauvelt A, Rifkin RM, et al. Switching reference medicines to biosimilars: a systematic literature review of clinical outcomes. Drugs 2018;78:463-78.
15 Inotai $\mathrm{A}$, Prins CPJ, Csanádi M, et al. Is there a reason for concern or is it just hype? - A systematic literature review of the clinical consequences of switching from originator biologics to biosimilars. Expert Opin Biol Ther 2017:17:915-26.

16 McKinnon RA, Cook M, Liauw W, et al. Biosimilarity and interchangeability: principles and evidence: a systematic review. BioDrugs 2018;32:27-52.

17 Blackwell K, Semiglazov V, Krasnozhon D, et al. Comparison of EP2006, a filgrastim biosimilar, to the reference: a phase III, randomized, double-blind clinical study in the prevention of severe neutropenia in patients with breast cancer receiving myelosuppressive chemotherapy. Ann Oncol 2015;26:1948-53.

18 Blauvelt A, Lacour J-P, Fowler JF, et al. Phase III randomized study of the proposed adalimumab biosimilar GP2017 in psoriasis: impact of multiple switches. Br J Dermatol 2018;179:623-31.

19 Glintborg B, Loft AG, Omerovic E, et al. To switch or not to switch: results of a nationwide guideline of mandatory switching from originator to biosimilar etanercept. One-year treatment outcomes in 2061 patients with inflammatory arthritis from the DANBIO registry. Ann Rheum Dis 2019;78:192-200.

20 Griffiths CEM, Thaçi D, Gerdes S, et al. The EGALITY study: a confirmatory, randomized, double-blind study comparing the efficacy, safety and immunogenicity of GP2015, a proposed etanercept biosimilar, vs. the originator product in patients with moderate-to-severe chronic plaque-type psoriasis. $\mathrm{Br} J$ Dermatol 2017;176:928-38.

21 Trifirò G, Marcianò I, Ingrasciotta Y. Interchangeability of biosimilar and biological reference product: updated regulatory positions and pre- and post-marketing evidence. Expert Opin Biol Ther 2018;18:309-15.

22 Medicines for Europe. Positioning statements on physicianled switching for biosimilar medicines, 2019. Available: https:// www.medicinesforeurope.com/wp-content/uploads/2017/03/MBiosimilars-Overview-of-positions-on-physician-led-switching.pdf [Accessed Apr2019].

23 Mason J. Semistructured interview. In: Lewis-Beck MS, Bryman A, Futing Liao T, eds. The SAGE encyclopedia of social science research methods. Thousand Oaks: Sage Publications, Inc, 2011. http://sk.sagepub.com/reference/socialscience. (accessed Apr 2019).

24 Edwards R, Holland J. What is qualitative interviewing? Available: http://eprints.ncrm.ac.uk/3276/1/complete_proofs.pdf [Accessed May 2019]

25 Richie J, Lewis J, Elam G, et al. Designing and selecting samples. In: Ritchie J, Lewis J, McNaughton Nicholls C, et al, eds. Qualitative research practice. A guide for social science students and researchers. Great Britain: SAGE Publications Ltd, 2014: 111-45.

26 Elo S, Kyngäs $\mathrm{H}$. The qualitative content analysis process. J Adv Nurs 2008;62:107-15.

27 Pope C, Ziebland S, Mays N. Analysing qualitative data. BMJ 2000;320:114-6.

28 Tong A, Sainsbury P, Craig J. Consolidated criteria for reporting qualitative research (COREQ): a 32-item checklist for interviews and focus groups. Int J Qual Health Care 2007;19:349-57.

29 Finnish National Board of Research Integrity. Ethical review in human sciences. Available: https://www.tenk.fi/en/ethical-review-in-humansciences [Accessed Aug 2018].

30 Pouillon L, Danese S, Hart A, et al. Consensus report: clinical recommendations for the prevention and management of the nocebo effect in biosimilar-treated IBD patients. Aliment Pharmacol Ther 2019;49:1181-7

31 Giuliani R, Tabernero J, Cardoso F, et al. Knowledge and use of biosimilars in oncology: a survey by the European Society for medical oncology. ESMO Open 2019;4:e000460.

32 Leonard E, Wascovich M, Oskouei S, et al. Factors affecting health care provider knowledge and acceptance of biosimilar medicines: a systematic review. JMCP 2019;25:102-12.

33 Scherlinger M, Langlois E, Germain V, et al. Acceptance rate and sociological factors involved in the switch from originator to biosimilar etanercept (Sb4). Semin Arthritis Rheum 2019;48:927-32

34 Heikkilä R, Mäntyselkä $\mathrm{P}$, Ahonen $\mathrm{R}$. Why people refuse generic substitution: a population survey of public opinion on generic substitution in Finland. Drugs Ther Perspect 2012;28:24-6.

35 Malassigné M, Megne-Wabo M, Rigalleau V, et al. 4CPS-008 Impact of pharmaceutical interview in patient acceptance of insulin glargine's biosimilar 100Ul/ml [abstract]. Eur J Hosp Pharm 2019;26.

36 Håkonsen $\mathrm{H}$, Eilertsen $\mathrm{M}$, Borge $\mathrm{H}$, et al. Generic substitution: additional challenge for adherence in hypertensive patients? Curr Med Res Opin 2009;25:2515-21. 
37 Bulsara C, McKenzie A, Sanfilippo F, et al. 'Not the full Monty': a qualitative study of seniors' perceptions of generic medicines in Western Australia. Aust J Prim Health 2010;16:240-5.

38 Gill L, Helkkula A, Cobelli N, et al. How do customers and pharmacists experience generic substitution? Intl $\mathrm{J}$ of Pharm \& Health Mrkt 2010;4:375-95.

39 European Medicines Agency and Heads of Medicines Agencies. Guideline on good pharmacovigilance practices (GVP), module XVI addendum I - educational materials. EMA/61341/2015. Available: https://www.ema.europa.eu/en/documents/regulatory-proceduralguideline/guideline-good-pharmacovigilance-practices-gvp-modulexvi-addendum-i-educational-materials_en.pdf [Accessed Apr 2019].

40 Finnish Medicines Act 396/, 1987. Available: https://www.finlex.fi/fi/ laki/ajantasa/1987/19870395 [Accessed Apr 2019].

41 European Medicines Agency. Biosimilar medicines: overview. Available: https://www.ema.europa.eu/en/human-regulatory/ overview/biosimilar-medicines-overview [Accessed May 2019].

42 Aladul MI, Fitzpatrick RW, Chapman SR. Healthcare professionals' perceptions and perspectives on biosimilar medicines and the barriers and facilitators to their prescribing in UK: a qualitative study. BMJ Open 2018;8:e023603.

43 European Medicines Agency. Good practice guide on risk minimisation and prevention of medication errors. Available: https:// www.ema.europa.eu/en/documents/regulatory-procedural-guideline/ good-practice-guide-risk-minimisation-prevention-medicationerrors_en.pdf [Accessed May 2019].

44 Beck M, Michel B, Rybarczyk-Vigouret M-C, et al. Rheumatologists' perceptions of biosimilar medicines prescription: Findings from a French web-based survey. BioDrugs 2016;30:585-92.

45 Danese S, Fiorino G, Michetti P. Changes in biosimilar knowledge among European Crohn's Colitis Organization [ECCO] members: An updated survey. ECCOJC 2016;10:1362-5.

46 Dolinar RO, Reilly MS. Biosimilars naming, label transparency and authority of choice - survey findings among European physicians. GaBI J 2014;3:58-62.

47 O'Callaghan J, Bermingham M, Leonard M, et al. Assessing awareness and attitudes of healthcare professionals on the use of biosimilar medicines: a survey of physicians and pharmacists in Ireland. Regul Toxicol Pharmacol 2017;88:252-61.

48 Gewanter HL, Reilly MS. Prescribing practices for biosimilars: questionnaire survey findings from physicians in Argentina, Brazil, Colombia and Mexico. GaBI Journal 2015;4:161-6.

49 Grabowski D, Henderson B, Lam D, et al. Attitudes towards subsequent entry biologics/biosimilars: a survey of Canadian rheumatologists. Clin Rheumatol 2015;34:1427-33.

50 Murby SP, Reilly MS. A survey of Australian prescribers' views on the naming and substitution of biologicals. GaBI J 2017;6:107-13.

51 Sarnola K, Merikoski M, Jyrkkä J, et al. Uptake of biosimilars in Finland - Physicians' views. Finnish Medicines Agency Fimea. Serial Publication Fimea Develops, Assesses and Informs 4/2019, 2019. Available: http://urn.fi/URN:ISBN:978-952-7299-02-9 [Accessed May 2019].

52 Chapman SR, Fitzpatrick RW, Aladul MI. Knowledge, attitude and practice of healthcare professionals towards infliximab and insulin glargine biosimilars: result of a UK web-based survey. BMJ Open 2017;7:e016730.

53 Olsson $\mathrm{E}$, Wallach-Kildemoes $\mathrm{H}$, Ahmed B, et al. The influence of generic substitution on the content of patient-pharmacist communication in Swedish community pharmacies. Int J Pharm Pract 2017;25:274-81.

54 Shrank WH, Liberman JN, Fischer MA, et al. The consequences of requesting "Dispense as Written". Am J Med 2011;124:309-17.
55 Egeth M, Soosaar J, Nash P, et al. Patient and healthcare professionals preference for Brenzys vs. Enbrel autoinjector for rheumatoid arthritis: a randomized crossover simulated-use study. Adv Ther 2017:34:1157-72.

56 Tischer B, Mehl A. Patients' and nurses' preferences for autoinjectors for rheumatoid arthritis: results of a European survey. Patient Prefer Adherence 2018;12:1413-24.

57 Fenwick S, Thakur K, Munro D. Nurse and patient perceptions and preferences for subcutaneous autoinjectors for inflammatory joint or bowel disease: findings from a European survey. Rheumatol Ther 2019;6:195-206.

58 Mellstedt $\mathrm{H}$. Clinical considerations for biosimilar antibodies. EJC Supp/ 2013;11:1-11.

59 Vermeer NS, Giezen TJ, Zastavnik S, et al. Identifiability of biologicals in adverse drug reaction reports received from European clinical practice. Clin Pharmacol Ther 2019;105:962-9.

60 Finnish Medicines Agency. Lääkkeiden toimittaminen. [in Finnish] Dnro Fimea 003223/00.01.02/, 2016. Available: https://www.fimea. fi/documents/160140/764653/M\%c3\%a4\%c3\%a4r\%c3\%a4ys. pdf/9332fa84-d115-41e2-b357-19eb28191312 [Accessed May 2019].

61 Kanta Services,. The social insurance institution of Finland. Prescribing a medicine. Available: https://www.kanta.fi/en/ professionals/prescribing-a-medicine [Accessed May 2019].

62 EudraLex. Directive 2011/62/EU of the European Parliament and of the Council of 8 June 2011 amending Directive 2001/83/EC on the community code relating to medicinal products for human use, as regards the prevention of the entry into the legal supply chain of falsified medicinal products. in: Union OJ L, ED. Brussels: Official Journal of the European Union, 2011.

63 EudraLex. Directive 2001/83/EC of the European Parliament and of the Council of 6 November 2001 on the community code relating to medicinal products for human use (consolidated version: 16/11/2012). Available: https://ec.europa.eu/health/documents/ eudralex/vol-1_en [Accessed May 2019].

64 Finnish Medicines Agency. Substitutable medicinal products. criteria used in compiling the list. Available: https://www.fimea.fi/web/ en/databases_and_registeries/substitutable_medicinal_products/ criteria_used_in_compiling_the_list [Accessed May 2019].

65 U.S. Department of Health and Human Services, Food and Drug Administration. Center for drug evaluation and research (CDER), center for biologics evaluation and research (CBER). considerations in demonstrating interchangeability with a reference product guidance for industry. Available: https://www.fda.gov/regulatoryinformation/search-fda-guidance-documents/considerationsdemonstrating-interchangeability-reference-product-guidanceindustry [Accessed May 2019].

66 O'Callaghan J, Barry SP, Bermingham M, et al. Regulation of biosimilar medicines and current perspectives on interchangeability and policy. Eur J Clin Pharmacol 2019;75:1-11.

67 Larkin H, Macdonald J, Lumsden R. Pharmacy-mediated substitution of biosimilars - a global survey benchmarking country substitution policies. GaBI J 2017;6:157-64.

68 Greene L, Singh RM, Carden MJ, et al. Strategies for overcoming barriers to adopting biosimilars and achieving goals of the biologics price competition and innovation act: a survey of managed care and specialty pharmacy professionals. J Manag Care Spec Pharm 2019;22:1-9.

69 Moorkens E, Vulto AG, Huys I, et al. Policies for biosimilar uptake in Europe: an overview. PLoS One 2017;12:e0190147.10.1371/journal. pone.0190147 